\title{
A Educação Física e o Esporte no contexto da universidade
}

Go TANI*

*Escola de Educação Física e Esporte, Universidade de São Paulo.

\section{Resumo}

0 objetivo do artigo foi discutir a Educação Física e o Esporte no contexto da universidade, isto é, como áreas de conhecimento. Procurou-se, inicialmente, descrever a missão e a função da universidade, identificando alguns desafios para o seu desempenho. A seguir a Educação Física e o Esporte foram abordados quanto ao seu processo histórico de estruturação como áreas de conhecimento. Apesar dos avanços observados, concluiu-se que uma melhor definição das suas identidades acadêmicas constituise um problema a ser ainda solucionado.

UnItermos: Educação física; Esporte; Área de conhecimento.

\section{Considerações iniciais}

As instituições de ensino superior no Brasil estão definidas pelo Decreto no. 3.860 de 9 de julho de 2001. Elas podem ser universidades, centros universitários, faculdades integradas, faculdades, institutos e escolas superiores, e centros de educação tecnológica. A definição baseia-se em critérios como a dimensão da instituição, a extensão das atividades de ensino e pesquisa desenvolvidas, os cursos de graduação e pós-graduação oferecidos, entre outros. Portanto, é importante fazer-se a devida distinção entre ensino superior e universidade, pois é muito comum confundir-se essas duas instituiçôes.

A universidade é entendida, de modo geral, como uma instituição que compreende um conjunto de faculdades, escolas ou institutos, identificados por especialidade profissional e científica, que tem por função precípua promover o avanço nas diversas áreas do conhecimento, por meio do ensino, da pesquisa e da extensão.

O presente artigo pretende discutir a Educação Física e o Esporte, como especialidades profissionais e científicas, no contexto da universidade. O seu objetivo não é, portanto, abordar seus problemas, desafios e perspectivas como prática de intervenção profissional na sociedade, mas sim como áreas de conhecimento inseridas numa instituição denominada de universidade.

\section{Da universidade}

Apesar do entendimento acerca da universidade já mencionado, não há um modelo único de universidade. As universidades compartilham alguns valores e princípios como liberdade acadêmica, ética, autonomia, mérito, qualidade e excelência (OLIVA, 2009), mas existe uma diversidade no que se refere a suas estruturas acadêmicas e administrativas e também a suas metas.

A função da universidade é ainda objeto de discussão no meio acadêmico (TANI, 2007) e talvez nunca o deixe de ser, em virtude das transformações sociais, culturais, científicas, econômicas e políticas às quais a universidade necessita estar sempre sintonizada para poder responder de forma competente e responsável às demandas. No entanto, há um reconhecimento geral de que ela deve desenvolver três atividades essenciais: o ensino, a pesquisa e a extensão, as chamadas atividades-fim da universidade. Naturalmente, isso não impede que numa determinada universidade as diferentes unidades que a compõe coloquem diferentes ênfases (não exclusividade) a essas três atividades em razão de suas condições e circunstâncias particulares. Por exemplo, em áreas ainda incipientes em termos acadêmico-científicos, há uma tendência de as atividades de ensino e de extensão se sobressaírem, o 
que faz com que o desafio e a expectativa institucionais recaiam, compreensivelmente, no desenvolvimento da pesquisa.

Dentro dessa diversidade existem as chamadas universidades de pesquisa. São normalmente instituições de grande porte que abarcam um grande número de especialidades científicas e profissionais. Nessas universidades, além do desenvolvimento das atividades de ensino, pesquisa e extensão, a indissociabilidade entre elas constitui um importante princípio norteador de suas ações. As razôes para a adoção desse princípio são variadas. Por exemplo, existe a compreensão de que o ensino sem a retaguarda da pesquisa que o alimente constantemente de novos conhecimentos tende a tornar-se obsoleto em pouco tempo. Além disso, entende-se que sem o acesso ao mundo da pesquisa para compreender o processo de produçãa do conhecimento, a formação profissional pode se tornar livresca, ou seja, caracterizada apenas pelo acúmulo de conhecimentos prontos e acabados engolidos "goela abaixo".

Ademais, compreende-se que a extensão sem sustentação na pesquisa corre o risco de se tornar um serviço assistencial de qualidade duvidosa. Da mesma forma, pensa-se que o ensino sem a extensão tende a ser uma formação sem o conhecimento da realidade e, portanto, incompleto e limitado. Na mesma linha de raciocínio, a pesquisa sem a devida articulação com o ensino e a extensão teria a propensão de perder a necessária vinculação com a especificidade da área, isto é, tornar-se um processo de produção de conhecimentos descontextualizados no que concerne às temáticas específicas da área. Em suma, o que se espera de uma universidade de pesquisa é que o ensino, a pesquisa e a extensão funcionem como um sistema em que a interação entre os componentes é fundamental para o alcance da meta.

Apesar de reconhecer-se a importância dessa indissociabilidade, a sua efetiva implementação não tem sido nada trivial. Na realidade, ela se constitui uma meta reguladora, muito mais do que uma prática difundida e consolidada. Nessas universidades, a pesquisa tem sido invariavelmente reconhecida e valorizada, não sem críticas, como o seu carro chefe, daí a sua própria denominação. Além de pautar as suas ações na já mencionada relação da pesquisa com o ensino e a extensão, é nessas universidades que se encontra a maior concentração de cursos de pós-graduação, os quais têm seu desenvolvimento diretamente ligado à pesquisa. Sabe-se que a pósgraduação é responsável, entre outras coisas, pela própria continuidade da instituição universitária, em virtude de ter como objetivo precípuo a formação de recursos humanos qualificados para a docência no ensino superior (TANI, 2000). Além disso, há sempre aquela justificativa de que a pesquisa, em nosso país, se faz prioritariamente nas universidades, pois elas foram originalmente concebidas para desempenhar tal função. Como se pode perceber, os argumentos que sustentam a ênfase à pesquisa são reconhecidamente muito fortes e convincentes, mas isso não lhes autoriza, obviamente, relegar as outras atividades a um plano secundário. As críticas procedem quando isso acontece.

É no momento das avaliações, seja de uma unidade, de um departamento, de um programa de pósgraduação, de um laboratório, de um grupo de estudo ou de um docente, que as críticas à supremacia da pesquisa surgem com mais contundência. As melhores avaliações são invariavelmente obtidas por aqueles que têm maior produção científica e isso é muitas vezes condição "sine qua non" para se obter mais recursos financeiros, mais recursos humanos, melhor infra-estrutura, mais bolsas de diferentes naturezas, e assim por diante. Como a maior parte das instituições universitárias tem o seu orçamento comprometido com o pagamento de pessoal, recursos para investimento em outras áreas devem ser buscados nas agências de fomento (FAPs, CNPq, CAPES, FINEP, entre outras). Quando se submete projetos para tal finalidade, o primeiro item a ser julgado é a produção científica do proponente, até mesmo quando se trata de obter recursos para fins coletivos, por exemplo, compra de livros para a biblioteca ou publicação de periódicos. Que se saiba, não existe sistema de bolsa ou outro tipo de recompensa implantado nas universidades e nas agências de fomento, para premiar de forma concreta a produtividade em ensino ou extensão, mas para a pesquisa se encontra em diferentes instâncias. Para assegurar a indissociabilidade do ensino, da pesquisa e da extensão, a universidade necessita criar mecanismos que efetivamente valorizem as três atividades, substituindo o discurso idealizado por uma prática concreta e consequente. Só assim o corpo docente deixará de dispensar atenção, dedicação e esforço prioritariamente à pesquisa e procurará atuar de forma a contribuir para a integração dessas três atividades.

Claro está que essas mudanças substantivas no "modus operandi" da universidade não podem ser feitas de forma apressada, muito menos leviana. No entanto, considerando-se que se trata de uma demanda antiga para a qual há um elevado índice de concordância interna, conclui-se que devem existir motivos robustos e consistentes para justificar essa 
resistência à mudança. Seriam eles de natureza política, econômica, conceitual, metodológica? Por exemplo, argumenta-se, reiteradamente, que as realizaçôes no ensino e na extensão são difíceis de serem avaliadas pela ausência de ferramentas como aquelas que são encontradas para a avaliação da pesquisa (classificação de periódicos, por exemplo). Mas, se essa dificuldade metodológica é real, não teria sido importante a universidade utilizar a sua "inteligência institucional" interna (supõe-se que existam muitos especialistas no assunto) para buscar soluçôes? Em outras palavras, não teria sido falta de vontade política (estabelecimento de prioridades) para dar o devido encaminhamento?

Como essa questão da indissociabilidade está no cerne da própria definição de universidade, a falta de iniciativa para equacionar o problema, fazendoa tornar-se realidade, leva a profundas indagaçóes acerca da própria natureza da universidade. Seria a universidade uma instituição conservadora, resistente às mudanças, em marcante contraste com a sua missão de transformação? Seria uma característica da universidade vigente ou da própria universidade? Seria a universidade capaz de resolver a dicotomia derivada de uma dupla necessidade, ou seja, recriar a sua época sendo ao mesmo tempo, uma criação de seu tempo (Leopoldo E Silva, 2006)?

Como se observa, a universidade se defronta com muitos problemas e desafios, que de certa forma atestam também a sua natureza dinâmica. Além dos já mencionados, existe o dilema da massificação do ensino e a manutenção de sua qualidade, o desafio da democratização do acesso e a política de inclusão social baseada no mérito, a necessidade de uma mudança cultural do ensino na direção do empreendedorismo, entre tantos outros de grande magnitude. Não é objetivo de este artigo identificá-los e discuti-los, sobretudo considerando que existe uma vasta e rica literatura que aborda especificamente essa matéria (veja, por exemplo, Rollemberg, 2005; Steiner \& Malnic, 2006).

No entanto, um desses desafios não pode deixar de ser mencionado, pois se trata de algo que, se ainda não sacode a universidade na sua base, o fará muito brevemente. É amplamente conhecido que a universidade influencia e tem sido influenciada pelo contexto histórico, social, cultural, econômico e político de cada época. Em cada momento ela teve seus problemas, desafios e obstáculos específicos. No presente, a universidade se defronta com um desafio muito especial, resultante de dois principais fatores: o crescimento vertiginoso no volume de conhecimentos da ciência contemporânea (revolução do conhecimento) e a evolução notável na tecnologia da informação quanto à abrangência e à velocidade na transmissão de informações (revolução da comunicação).

Em virtude desses dois fatores, a universidade perdeu a hegemonia do conhecimento, particularmente no domínio de sua disseminação, o que a fez mergulhar numa violenta crise de identidade. Se, antes da chamada revolução da comunicação ou da informação, iniciada com a criação do computador, era compulsória a ida à universidade para ter acesso aos conhecimentos sistematizados e acumulados historicamente pelas diferentes disciplinas científicas, hoje não é exagero afirmar que para tal finalidade específica - acesso ao conhecimento - ir à universidade pode se constituir uma boa forma de perder tempo. Comparativamente à Internet, por exemplo, a universidade é uma instituição lenta, arcaica, pesada e ineficiente no que se refere ao acesso ao conhecimento, tanto em quantidade quanto em velocidade.

Esse novo cenário coloca em cheque o modelo tradicional de ensino que ainda persiste na universidade e a faz refletir sobre a sua própria função social. Certamente, a forma como a universidade irá responder a essa crise definirá, em boa medida, o seu futuro.

Considerando esse "background" que envolve a universidade, pretende-se abordar, a seguir, a Educação Física e o Esporte como áreas de conhecimento. Antes, porém, julga-se oportuno trabalhar com alguns conceitos adicionais para detalhar um pouco mais o pano de fundo.

\section{Das especialidades profissionais e científicas}

As profissões podem ser classificadas segundo diferentes critérios. De acordo com a formação profissional que é esperada, requerida ou exigida para o seu exercício, elas podem ser classificadas em tecnicamente orientadas e academicamente orientadas. Nas profissões tecnicamente orientadas, essa formação acontece, na maioria das vezes, no ensino médio, nas chamadas escolas técnicas profissionalizantes. As profissões academicamente orientadas, por sua vez, são aquelas em que o exercício profissional pressupõe uma formação de nível superior (TANI, 2008). 
Um requisito básico de numa profissão academicamente orientada é a existência de um corpo de conhecimentos acadêmico-científicos em que se baseiam suas propostas, projetos e procedimentos de intervenção profissional. Assim posto, uma importante questão é saber que corpo de conhecimentos é esse e como ele é produzido e sistematizado.

A universidade, como foi visto, contempla uma diversidade de especialidades profissionais e científicas ou áreas de conhecimento. Essas áreas são normalmente classificadas em três grandes grupos por afinidade acadêmico-científica no que se refere ao objeto de estudo: ciências humanas, biológicas e exatas. Existem outras classificaçōes como aquela adotada pelo CNPq - Conselho Nacional de Desenvolvimento Científico e Tecnológico - que identifica três grandes áreas: engenharias, ciências exatas e da terra; ciências humanas e sociais aplicadas; e ciências da vida. A Educação Física e o Esporte se enquadram nas ciências biológicas e ciências da vida, respectivamente.

Outro critério para se classificar as áreas de conhecimento é o tipo de pesquisa que realiza: básicas, aplicadas ou tecnológicas. Como largamente conhecido, essas pesquisas interagem fortemente entre si, mas cada uma tem característica própria (TANI, 2008). A pesquisa básica busca a compreensão ou a explicação do objeto de estudo; sua motivação é o conhecimento pelo conhecimento, saciar a curiosidade, desvendar o mundo desconhecido; sua pretensão é contribuir para o enriquecimento cultural da humanidade. A pesquisa aplicada busca o aperfeiçoamento da práxis, ou seja, produzir conhecimento de aplicação prática para solucionar problemas reais e imediatos da sociedade. A pesquisa tecnológica, por sua vez, procura desenvolver produtos e serviços a partir dos conhecimentos anteriores.

Essa classificação por tipo de pesquisa tem também uma forte relação com as concepções de ciência. É amplamente conhecido que se tem, basicamente, duas concepções: a) como um empreendimento que tem como objetivo estudar fenômenos e eventos de natureza física, social ou cultural, buscando a sua descrição, explicação e predição; e b) como um empreendimento que deve servir a humanidade, isto é, fornecer soluções para problemas que são importantes para a sociedade. Claramente, existe uma relação muito próxima entre a primeira concepção de ciência com a pesquisa básica e a segunda com a pesquisa aplicada e tecnológica.

Essas duas concepções de ciência podem levar pessoas a diferentes posições e valorizaçōes quanto ao tipo de pesquisa, muitas vezes motivadas por inclinações ideológicas de natureza sociopolítica. O sentido "desinteressado" da pesquisa básica pode levar algumas a considerarem-na neutra e menos relevante, visto que não se vincula a problemas reais e prementes da sociedade. Ao contrário, o sentido prático da pesquisa aplicada e tecnológica de se orientar para a solução desses problemas pode induzir outras a considerarem-nas mais compromissadas e lhes atribuírem valor mais elevado, ou seja, de serem socialmente mais relevantes porquanto trazem benefícios imediatos. $\mathrm{Na}$ realidade, essas posiçōes não levam em consideração a forte interação e interdependência existente entre esses tipos de pesquisa, que muitas vezes demoram em se tornar evidentes. Dessa forma, a posição consensual é aquela que as concebe como complementares e não excludentes, defendendo, portanto, a interação e integração cada vez maior e mais intensa dos três tipos de pesquisa.

Essas considerações sobre concepções de ciência, tipos de pesquisa e tipos de profissões são fundamentais para a discussão da identidade acadêmica e profissional de cada especialidade. Em outras palavras, a definição da identidade de uma área de conhecimento, expressando de forma clara se é de natureza básica, aplicada ou tecnológica, é absolutamente indispensável para que as atividades de pesquisa realizadas no seu interior tenham coerência com essa definição, e os conhecimentos produzidos tenham pertinência assegurada para poderem contribuir com o seu crescimento (TANI, 1996, 1998, 2008). A ausência dessa definição pode estimular os pesquisadores a "atirarem para todos os lados" e os seus esforços ficarem diluídos sem resultar em conhecimentos articulados em torno de objetos, temas e problemas específicos da área em que atuam. Isso não pode, obviamente, ser confundido com tornar a área isolada e fechada em si mesma, mesmo porque a troca de ideias, conhecimentos e tecnologias entre as áreas será cada vez maior e mais intensa na ciência moderna (TANI, 2008).

A definição de identidade é também fundamental quando se analisa as suas implicaçōes na preparação profissional. As áreas de conhecimento aplicadas são também conhecidas como áreas profissionalizantes ou de intervenção, isto porque elas estão associadas a uma profissão específica em que a atuação profissional está muitas vezes regulamentada e protegida por associações de classe. A preparação profissional numa área profissionalizante não seria possível na ausência de um corpo de conhecimentos específicos próprios de natureza aplicada (TANI, 2008). 


\section{Da profissão e a sua relação com a área de conhecimento}

A Educação Física e o Esporte fazem parte das profissōes denominadas academicamente orientadas. Portanto devem possuir um corpo de conhecimentos acadêmico-científicos em que se baseiam suas propostas, programas e procedimentos de intervenção profissional. É bem sabido que a inexistência do suporte desse corpo de conhecimentos coloca em cheque não apenas a legitimidade, mas também a própria existência e sobrevivência dessas profissões (TANI, 2008).

É importante salientar que apesar de existirem diferentes tipos de conhecimentos úteis à prática profissional - como aqueles de natureza pessoal e profissional - assume-se que a legitimidade social e profissional de uma profissão passa necessariamente pela legitimidade do corpo de conhecimentos acadêmico-científico. Daí concluir-se que esses conhecimentos são aqueles que devem constituir a base estrutural que dá sustentação a uma profissão academicamente orientada.

A legitimidade acadêmico-científica do corpo de conhecimentos, por sua vez, pressupõe uma estrutura que organize a produção, a sistematização, a disseminação e a aplicação de conhecimentos, atribuindo-lhe uma identidade que possibilite a sua caracterização como uma área específica de conhecimento. A essa estrutura dá-se o nome de base epistemológica da área e ao conjunto de conceitos compartilhados que viabiliza a comunicação interna, o nome de estatuto epistemológico. Portanto, a definição de identidade acadêmica e sua consolidação mediante pesquisas científicas abrangentes e profundas podem ser entendidas como uma necessidade imperativa para a Educação Física e o Esporte.

\section{A Educação Física e o Esporte como áreas de conhecimento}

A Educação Física e o Esporte são áreas de conhecimento de história relativamente curta no contexto da universidade. Sua função é produzir conhecimento e disseminá-lo, por meio do ensino, da pesquisa e da extensão. A justificativa de suas presenças no contexto da universidade depende do desempenho fiel dessa função.

A Educação Física, especificamente, tem uma história relativamente longa como uma prática profissional e como um curso de preparação profissional. No entanto, como uma área de conhecimento ela é ainda incipiente. No Brasil, os esforços mais sistemáticos em direção à estruturação da sua base acadêmicocientífica iniciaram-se, fundamentalmente, na década de 80 com a implantação da pós-graduação "stricto sensu" (Mestrado e Doutorado). Até então, acreditava-se que os conhecimentos científicos que a Educação Física necessitava para a formação de seus profissionais estavam disponíveis em outras áreas do conhecimento, especialmente nas chamadas ciências mãe (Física, Biologia, Psicologia, Sociologia, etc.).

A implantação da pós-graduação inaugurou uma nova fase da Educação Física em nosso país, visto que foi ela que a inseriu, de fato, no universo acadêmico (TANi, 1996). Como é bem conhecido, pós-graduação é essencialmente pesquisa. O retorno de muitos doutores e mestres formados no exterior, em coincidência com a implantação dos primeiros programas, foi também decisivo para dar impulso à criação de uma estrutura para a produção do conhecimento e formação de recursos humanos qualificados para a docência no ensino superior e para a pesquisa.

No contexto internacional, o acontecimento mais marcante na história da Educação Física como uma área de conhecimento deu-se nos EUA na década de 60, quando Henry (1964) propôs os fundamentos epistemológicos da Educação Física - uma área de conhecimento relacionada com a investigação da natureza e significado do movimento humano em suas várias formas e manifestaçōes. Em outras palavras, uma área de estudo relacionada com a investigação da natureza e significado do movimento humano em suas várias formas e com o estudo não só do como, mas também do porquê da atividade física (KROLL, 1982).

A partir dessa proposição seminal de Henry, os anos que se seguiram foram caracterizados por um interesse crescente pela pesquisa. A tendência observada foi a especialização cada vez mais intensa dos temas investigados que, por sua vez, deu origem à criação de várias subáreas, cada qual com seus objetivos e preocupações acadêmicas próprias. Essas subáreas se organizaram de tal maneira que criaram suas associações próprias, seus congressos específicos e seus veículos de publicação especializados. As principais subáreas que emergiram inicialmente foram as de Fisiologia do Exercício, Biomecânica, 
Aprendizagem Motora / Psicologia do Esporte, Sociologia e Educação do Esporte, História e Filosofia da Educação Física e Teoria Administrativa em Esporte e Educação Física (PARK, 1989).

O resultado concreto desse processo de estruturação como uma área de conhecimento foi um inegável avanço acadêmico-científico, evidenciado, entre outras coisas, pelo aumento significativo no volume de estudos conduzidos, no número de periódicos especializados, na quantidade de eventos científicos realizados, no número de publicações até mesmo publicações em periódicos de reputação em áreas de maior tradição acadêmica. Na literatura especializada esse processo é conhecido como "movimento disciplinar" da Educação Física, pelo fato de Henry (1964) ter concebido a Educação Física como uma disciplina acadêmica.

O movimento disciplinar deu origem também a uma redefinição da denominação da área e abriu espaço para uma proliferação de nomenclaturas em substituição à tradicional Educação Física. Denominações como Ciências do Movimento, Ciências da Atividade Física, Ciências do Esporte e Cinesiologia foram utilizados para identificar não apenas a área, mas também departamentos, cursos de formação profissional e sociedades científicas.

O fato de a Educação Física e o Esporte serem tratados nesse artigo como áreas de conhecimento relacionadas, porém distintas, decorre de uma proposta apresentada pelo autor (TANI, 1996) para tentar equacionar não apenas a ambiguidade resultante dessa proliferação de denominações, mas também para diferenciar áreas de conhecimento de natureza acadêmica e profissionalizante. Como não havia até então uma clara diferenciação entre as duas áreas, o termo Educação Física era utilizado de forma genérica para se referir a ambas. Em virtude disso, pode parecer, à primeira vista, que só a Educação Física está sendo discutida e analisada e o Esporte esquecido, o que obviamente não corresponde.

A Educação Física e o Esporte no Brasil foram fortemente influenciados por esse "movimento disciplinar", tendo o paradigma sido incorporado na estruturação dos laboratórios, na definição de áreas de concentração na pós-graduação, no estabelecimento de linhas de pesquisa e também nos currículos de formação profissional. Existe hoje no nosso país uma complexa estrutura de produção, sistematização e disseminação de conhecimentos científicos baseada fundamentalmente nos pilares desse movimento.

Essa estrutura contempla várias subáreas de pesquisa que seguem em linhas gerais aquelas que existem no cenário internacional. Entre as subáreas de pesquisas mais básicas tem-se, por exemplo, dos níveis mais microscópicos de análise para o mais macroscópicos, a Bioquímica do Exercício, a Fisiologia do Exercício, a Biomecânica, o Controle Motor, a Cineantropometria, o Desenvolvimento Motor, a Aprendizagem Motora, a Psicologia do Esporte/Atividade Física, a Sociologia do Esporte/Educação Física, a Antropologia do Esporte/ Educação Física, a História do Esporte/Educação Física e a Filosofia do Esporte/Educação Física. Por outro lado, nas subáreas de pesquisas mais aplicadas tem-se, por exemplo, a Nutrição Aplicada ao Esporte/Atividade Física, o Treinamento Esportivo, a Administração Esportiva, a Pedagogia do Esporte/Educação Física, a Educação Física Adaptada, a Educação Física Escolar, a Educação Física Laboral, o Lazer e Recreação, o Jornalismo Esportivo, o "Marketing" Esportivo e o Direito Esportivo.

A produção de conhecimentos teve uma evolução notável nesses últimos anos tanto quantitativa como qualitativamente (veja, por exemplo, KoKUBUn, 2003). Muitos pesquisadores da área têm publicaçôes em periódicos internacionais de alto impacto e os programas de pós-graduação aproximam-se cada vez mais de critérios internacionais de qualidade. Várias associaçóes científicas de diferentes especialidades foram criadas e essa tendência de crescente diferenciação e especialização parece não perder o seu ímpeto. O número de eventos científicos cresce regularmente e tem-se uma quantidade substancial de periódicos especializados, vários deles com indexação internacional. Todavia, nem por isso estamos livres de problemas basilares.

Acompanhando a mesma tendência observada em outros países, tudo indica que a meta da Educação Física e do Esporte em nosso país, no âmbito da produção de conhecimentos, foi e tem sido ainda a obtenção do "status" e respeitabilidade acadêmicos. Isso implicou dar muita ênfase à pesquisa básica em detrimento de pesquisas aplicadas comprometidas com solução de problemas encontrados na prática profissional. De fato, uma das consequências do "movimento disciplinar" foi uma ênfase quase que exclusiva à pesquisa de natureza básica, o que resultou num abandono de estudos de temas profissionalizantes e aplicados que abordassem problemas relevantes encontrados na intervenção. Corroborando essa afirmação, os avanços científicos frequentemente apontados e enaltecidos como aqueles que têm elevado o "status" acadêmico têm ocorrido, basicamente, nas subáreas de pesquisa básica.

A repetição dessa tendência no nosso meio tem gerado inquietações no interior da área. Para 
muitos pesquisadores, as necessidades da profissão devem orientar a natureza e conteúdo da atividade acadêmica de uma área, ou seja, as necessidades correntes e futuras da profissão devem ditar os tipos de perguntas a serem formulados pelos pesquisadores associados à área. Dentro dessa linha de raciocínio, a busca do conhecimento pelo conhecimento deve acontecer nas áreas comumente denominadas de puras ou básicas, em que não se tem preocupações com a sua aplicação prática por não haver nenhuma vinculação a um campo profissional específico.

O movimento disciplinar acreditou, inicialmente, que as pesquisas desenvolvidas nessas subáreas pudessem contribuir para a formação de um corpo integrado de conhecimentos que desse uma identidade acadêmica à área e uma sustentação teórica à prática e à preparação profissional. Entretanto, o que se observou foi uma fragmentação do conhecimento (HOFFMAn, 1985; TANi, 1988; ThOMAS, 1987) com cada subárea preocupada em estudar problemas crescentemente específicos, sem articulação entre si. A especialização progressiva é um processo de certo modo inevitável nas chamadas ciências básicas de orientação vertical. Nas ciências aplicadas, ao contrário, o que se requer são pesquisas de síntese e integração de conhecimentos.

Infelizmente, a fragmentação do conhecimento já atinge o nosso país. A maioria dos nossos laboratórios está estruturada segundo orientações do movimento disciplinar. As disciplinas curriculares, tanto dos cursos de graduação como de pós-graduação, mantêm correspondência com essa forma de produção de conhecimentos. Associações científicas específicas de cada subárea têm sido criadas, e cada uma delas

\section{Considerações finais}

É amplamente reconhecido que a Educação Física e o Esporte em nosso país avançaram muito nessas últimas décadas no campo da produção científica. No entanto, para se avaliar os impactos desse avanço no desenvolvimento dessas áreas é importante uma definição clara das suas identidades acadêmicas. Caso a Educação Física e o Esporte sejam entendidos e caracterizados como áreas de conhecimento de natureza acadêmica, provavelmente a avaliação dos avanços será extremamente positiva. Ao contrário, se os concebermos como áreas de intervenção, ou seja, profissionalizantes, essa avaliação será seguramente diferente. tem realizado eventos científicos específicos e editado publicações também específicas. Por exemplo, a Sociedade Brasileira de Atividade Motora Adaptada, a Sociedade Brasileira de Biomecânica, a Sociedade Brasileira de Comportamento Motor, a Sociedade Brasileira de Fisiologia do Exercício, a Sociedade Brasileira de Psicologia do Esporte, o Grupo de História do Esporte, Lazer e Educação Física entre outras. Pouca comunicação tem existido entre as subáreas, e pior ainda, dentro de cada subárea formam-se grupos ainda menores e fechados para investigar problemas crescentemente específicos.

A fragmentação do conhecimento pode ter diferentes implicaçóes dependendo de como se identifica a Educação Física e o Esporte: áreas de pesquisa básica, aplicada ou ambas. Como essa identificação ainda não existe, assiste-se a uma disputa entre os defensores da área como sendo acadêmica (científica) ou profissionalizante (de intervenção).

A solução para esse problema implica uma ampla reflexão sobre a base epistemológica da área, o que se constitui um dos maiores desafios da Educação Física e do Esporte. Infelizmente, são ainda poucos os pesquisadores no nosso meio, que têm se envolvido diretamente com essa problemática, ou seja, uma melhor definição da identidade acadêmica da Educação Física e do Esporte. Ciente do risco de omitir alguns nomes importantes é possível destacar entre os pesquisadores interessados os seguintes, com as suas respectivas contribuiçôes representativas: BETTI (1996, 2005, 2007); BRACHT (1993, 1995a, 1995b, 2000, 2003, 2009); GAYA (1992, 1994, 2006); KoKUBun (1995, 2006); Kunz (1998, 2006, 2007); LoVISOlo (1995, 1996); Moreira (1992, 2006); Pereira da Costa $(1996,2003)$.

Um importante desafio se coloca às áreas de Educação Física e Esporte no Brasil: seguir os mesmos caminhos trilhados e os percalços experimentados por outros países ou optar por um salto qualitativo. Tudo indica que a segunda alternativa seria a mais racional, mas isso implica açōes concretas como evitar aprofundamento ainda maior do embate em torno de suas caracterizações como área acadêmica ou profissionalizante, discutir seriamente a não intensificação da fragmentação do conhecimento, buscar consenso em relação à nomenclatura das áreas, enfim, definir uma identidade que possa orientar a produção, a sistematização, a disseminação e a aplicação de conhecimentos. 
Excetuando-se os temas relativos ao meu campo específico de investigação, que é a Aprendizagem Motora, as discussões acerca desse assunto têm sido uma das minhas maiores preocupações acadêmicas nos últimos anos, tendo resultado em algumas publicaçôes (TANI, 1988, 1989, 1996, 1998, 1999, 2006, 2008). O objetivo central desses trabalhos tem sido o de contribuir para aprofundar as reflexões, discussões e proposiçōes acerca do tema. Como a minha visão da identidade acadêmica da Educação Física e do Esporte já foram apresentadas em textos anteriores, aos interessados tomo a liberdade de sugerir a leitura dos originais.

\begin{abstract}
Physical Education and Sport in the context of university

The objective of this article was to discuss Physical Education and Sport as fields of knowledge in the university context. Initially, the mission and the role of the university were described, and as a result some challenges to accomplish them were identified. Next, the historical structuring process of Physical Education and Sport as fields of knowledge was discussed. It was concluded that, despite observed advancement a better definition of their academic identities constitutes a problem still to be solved.
\end{abstract}

UnITERMS: Physical education; Sport; Field of knowledge.

\title{
Referências
}

BETTI, M. Educação física como prática científica e prática pedagógica: reflexões à luz da filosofia da ciência. Revista Brasileira de Educação Física e Esporte, São Paulo, v.19, p.183-97, 2005.

Educação física e cultura corporal de movimento: uma perspectiva fenomenológica e semiótica. Revista da

Educação Física/UEM, Maringá, v.18, p.207-17, 2007.

. Por uma teoria da prática. Motus Corporis, Rio de Janeiro, v.3, p.73-127, 1996.

BRACHT, V. 30 anos de CBCE: os desafios de uma associação científica. Revista Brasileira de Ciências do Esporte, Campinas, v.30, p.31-44, 2009.

. As ciências do esporte no Brasil: uma avaliação crítica. In: FERREIRA NETO, A.; GOELLNER, S.V.; BRACHT,

V. (Orgs.). As ciências do esporte no Brasil. Campinas: Autores Associados, 1995a. p.29-49.

Educação física/ciências do esporte: que ciência é essa? Revista Brasileira de Ciências do Esporte, Campinas, v.14, p.111-7, 1993.

. Educação física \& ciência: cenas de um casamento (in)feliz. Revista Brasileira de Ciências do Esporte, Campinas, v.22, p.53-63, 2000 .

Identidade e crise da educação física: um enfoque epistemológico. In: BRACHT, V.; CRISÓRIO, R. (Orgs.). A

educação física no Brasil e na Argentina: identidade, desafios e perspectivas. Campinas: Autores Associados, 2003. p.13-29.

. Mas, afinal, o que estamos perguntando com a pergunta "o que é educação física?” Movimento, Porto Alegre, v.2, p.I-VIII, 1995 b.

GAYA, A.C.A. Corpos esportivos: o esporte como campo de investigação científica. In: TANI, G.; BENTO, J.O.; PETERSEN, R.D.S. (Eds.). Pedagogia do desporto. Rio de Janeiro: Guanabara Koogan, 2006. p.101-12.

Mas, afinal, o que é educação física? Movimento, Porto Alegre, v.1, p.29-34, 1994.

Por uma ciência do desporto para além do empirismo ativista e do intelectualismo militante. In: BENTO, J.;

MARQUES, A. (Eds.). A ciência do desporto, a cultura e o homem. Porto: Universidade do Porto, 1992. p.79-90.

HENRY, F.M. Physical education: an academic discipline. Journal of Physical Education and Recreation, Reston, v.35, p.32-8, 69, 1964.

HOFFMAN, S.J. Specialization + fragmentation = extermination: a formula for the demise of graduate education. Journal of Physical Education and Recreation and Dance, Reston, v.56, p.19-22, 1985. 
KOKUBUN, E. Negação do caráter filosófico-científico da educação física: reflexōes a partir da biologia do exercício. In: FERREIRA NETO, A.; GOELLNER, S.V.; BRACHT, V. (Orgs.). As ciências do esporte no Brasil. Campinas: Autores Associados, 1995. p.53-69.

. Pós-graduação em educação física. Revista Brasileira de Educação Física e Esporte, São Paulo, v.20, p.31-3, 2006.

. Pós-graduação em educação física no Brasil: indicadores objetivos dos desafios e das perspectivas. Revista Brasi-

leira de Ciências do Esporte, Campinas, v.24, p.9-26, 2003.

KROLL, W.P. Graduate study and research in physical education. Champaign: Human Kinetics, 1982.

KUNZ, E. Ciências do esporte, da educação física e do movimento humano: prioridades, privilégios e perspectivas. In: CARVALHO, Y.; LINHALES, M. (Orgs.). Política científica e produção do conhecimento em educação física. Goiânia: Universidade Federal de Goiás, 2007. p.87-106.

. Limitações no fazer ciência em educação física e esportes: CBCE - 20 anos auxiliando na superação. Revista

Brasileira de Ciências do Esporte, Campinas, p.4-11, 1998. Número especial.

. Pedagogia do esporte, do movimento humano ou da educação física? In: KUNZ, E.; TREBELS, A.H. (Orgs.).

Educação física crítico emancipatória: com uma perspectiva da pedagogia alemã do esporte. Ijuí: Unijuí, , 2006. p.11-23. LEOPOLDO E SILVA, F. Universidade: a idéia e a história. In: STEINER, J.E.; MALNIC, G. (Orgs.). Ensino superior: conceito e dinâmica. São Paulo: Editora da Universidade de São Paulo, 2006. p.285-96.

LOVISOLO, H. Hegemonia e legitimidade nas ciências dos esportes. Motus Corporis, Rio de Janeiro, v.3, p.51-72, 1996. . Mas, afinal, o que é educação física? A favor da mediação e contra os radicalismos. Movimento, Porto Alegre, v.2, p.XVIII-XXIV, 1995.

MOREIRA, W.W. Por uma concepção sistêmica na pedagogia do movimento. In: (Org.). Educação física e esportes: perspectivas para o século XXI. Campinas: Papirus, 1992. p.199-210.

MOREIRA, W.W.; CARBINATTO, M.V. Bases epistemológicas, a educação física e o esporte: possibilidades. RRevista Brasileira de Educação Física e Esporte, São Paulo, v.20, p.128-31, 2006.

OLIVA, G. Modelo de universidade, missão e visão de futuro. In: VILELA, S.; LAJOLO, F.M. (Orgs.). USP 2034: planejando o futuro. São Paulo: Editora da Universidade de São Paulo, 2009. p.45-72.

PARK, R.J. The second 100 years: or can physical education become the renaissance field of the 21th Century? Quest, Champaign, v.41, p.1-27, 1989.

PEREIRA DA COSTA, L. Uma questão ainda sem resposta: o que é educação física. Movimento, Porto Alegre, v.4, p.I-X, 1996. PEREIRA DA COSTA, L.; DUARTE, C.P. O debate epistemológico da educação física no âmbito dos cursos de pósgraduação stricto sensu reinterpretado por contribuiçōes da teoria da complexidade de Morin. Revista Brasileira de Ciências do Esporte, Campinas, v.24, p.132-40, 2003.

ROLLEMBERG, M. (Org.) Universidade: formação \& transformação. São Paulo: Editora da Universidade de São Paulo, 2005. STEINER, J.E.; MALNIC, G. (Orgs.). Ensino superior: conceito e dinâmica. São Paulo: Editora da Universidade de São Paulo, 2006.

TANI, G. 20 anos de ciências do esporte: um transatlântico sem rumo? Revista Brasileira de Ciências do Esporte, Campinas, p.19-31, 1998. Número especial.

Área de conhecimento e intervenção profissional. In: CORRÊA, U.C. (Org.). Pesquisa em comportamento motor: a intervenção profissional em perspectiva. São Paulo: Escola de Educação Física e Esporte da Universidade de São Paulo, 2008. p.14-25. Atividade de pesquisa na Escola de Educação Física e Esporte da Universidade de São Paulo: passado, presente e

futuro. Revista Paulista de Educaçáo Física, São Paulo, v.13, p.20-35, 1999. Número especial.

. Avaliação das condiçōes do ensino de graduação em educação física: garantia de uma formação de qualidade.

Revista Mackenzie de Educação Física e Esporte, São Paulo, v.6, n.2, p.55-70, 2007.

Cinesiologia, educação física e esporte: ordem emanente do caos na estrutura acadêmica. Motus Corporis, Rio de Janeiro, v.3, p.9-50, 1996.

. Comportamento motor e sua relação com a educação física. Brazilian Journal of Motor Behavior, Rio Claro, v.1, p.21-30, 2006.

. Os desafios da pós-graduação em educação física. Revista Brasileira de Ciências do Esporte, Campinas, v.22, p.79-90, 2000. Perspectivas da educação física como disciplina acadêmica. In: SIMPÓSIO PAULISTA DE EDUCAÇÃO FÍSICA,

2., 1989, Rio Claro. Anais... Rio Claro: Universidade Estadual Paulista, 1989. v.2, p.2-12.

. Pesquisa e pós-graduação em educação física. In: PASSOS, S.C.E. (Org.). Educação física e esportes na universidade. Brasília: SEED-MEC/UnB, 1988.

THOMAS, J.R. Are we already in peaces, or just falling apart? Quest, Champaign, v.39, p.114-21, 1987. 
TANI, G.

ENDEREÇO

Go Tani

Escola de Educação Física e Esporte - USP

Av. Prof. Mello Moraes, 65

05508-030 - São Paulo - SP - BRASIL

e-mail: gotani@usp.br

126 • Rev. bras. Educ. Fís. Esporte, São Paulo, v.25, p.117-26, dez. 2011 N. esp. 